Preparation and characterization of bioactive glass nanoparticles prepared by sol-gel for biomedical applications

This article has been downloaded from IOPscience. Please scroll down to see the full text article.

2011 Nanotechnology 22494014

(http://iopscience.iop.org/0957-4484/22/49/494014)

View the table of contents for this issue, or go to the journal homepage for more

Download details:

IP Address: 193.137.16.115

The article was downloaded on 21/11/2011 at 11:50

Please note that terms and conditions apply. 


\title{
Preparation and characterization of bioactive glass nanoparticles prepared by sol-gel for biomedical applications
}

\author{
Gisela M Luz and João F Mano \\ 3B's Research Group-Biomaterials, Biodegradables and Biomimetics, University of Minho, \\ Headquarters of the European Institute of Excellence on Tissue Engineering and Regenerative \\ Medicine, AvePark, P-4806-909 Taipas, Guimarães, Portugal \\ and \\ ICVS/3B's—PT Government Associate Laboratory, Portugal \\ E-mail: gisela.luz@dep.uminho.pt and jmano@dep.uminho.pt
}

Received 27 May 2011, in final form 2 August 2011

Published 21 November 2011

Online at stacks.iop.org/Nano/22/494014

\begin{abstract}
Bioactive glass nanoparticles (BG-NPs), based on both ternary $\left(\mathrm{SiO}_{2}-\mathrm{CaO}-\mathrm{P}_{2} \mathrm{O}_{5}\right)$ and binary $\left(\mathrm{SiO}_{2}-\mathrm{CaO}\right)$ systems, were prepared via an optimized sol-gel method. The $\mathrm{pH}$ of preparation and the effect of heat treatment temperature were evaluated, as well as the effect of suppressing $\mathrm{P}$ in the bioactivity ability of the materials. The morphology and composition of the BG-NPs were studied using FTIR, XRD and SEM. The bioactive character of these materials was accessed in vitro by analyzing the ability for apatite formation onto the surface after being immersed in simulated body fluid (SBF). XRD, EDX and SEM were used to confirm the bioactivity of the materials. The BG-NP effect on cell metabolic activity was assessed by seeding L929 cells with their leachables, proving the non-cytotoxicity of the materials. Finally the most bioactive BG-NPs developed (ternary system prepared at $\mathrm{pH} 11.5$ and treated at $700{ }^{\circ} \mathrm{C}$ ) were successfully combined with chitosan in the production of biomimetic nanocomposite osteoconductive membranes that could have the potential to be used in guided tissue regeneration.
\end{abstract}

\section{Introduction}

When bioactive glasses were discovered, they radically changed the biomaterials field. For the first time, a chemical bond between implants and host tissue was possible, leaving behind a first generation of bioinert devices. This was the beginning of a second generation of bioactive materials capable of inducing a cellular response at their surface. These materials were able to bond not only to bone, but to soft tissue as well, avoiding fibrous encapsulation [1,2]. Moreover, the broad scope of the possible compositions leads to different chemical properties and rate of bonding with tissues, allowing more specific clinical applications [3].

The first bioactive glass developed by Hench in 1971 was composed of $\mathrm{SiO}_{2}, \mathrm{CaO}, \mathrm{Na}_{2} \mathrm{O}$ and $\mathrm{P}_{2} \mathrm{O}_{5}$ (Bioglass ${ }^{\circledR}$ ) [2]. The first bioactive glasses were produced by melting the required materials and casting of the bulk or quenching of powders [2]. In 1991, Li et al produced bioactive glasses by sol-gel processing [4]. Sol-gel is a wet-chemical processing method more appropriate to produce these glasses as an alternative to the traditional melting method, because it allows a wider range of $\mathrm{SiO}_{2}$ content and higher purity of the obtained products [5].

The $\mathrm{SiO}_{2}-\mathrm{CaO}-\mathrm{P}_{2} \mathrm{O}_{5}$ system is one of the most extensively studied in the field of bioactive sol-gel glasses [6-9]. However, the majority of these bioactive glasses are prepared by direct heating of the gels, after allowing gelation to occur, which results in a hard block that must be ground and sieved to reach particle sizes at the microscale. Microsized particles of bioactive glasses are commonly used, but there are not many works exploring the advantages of using nanosized particles.

Nanoparticles have sizes of the order of 10-100 nm in diameter and, unlike bulk materials, the biological response of these particles is highly dependent on their dimensions and specific surface area $[10,11]$. Bioactive glass nanoparticles may have a significant function as well in the genetic control of the cellular response. Additionally, 
their particular characteristics which have anti-inflammatory and proangiogenic potential are ideal for applications like minimally invasive injectable particles for stable growth of soft tissues $[12,13]$.

The use of particles within the nanoscale may open new possibilities in the biomedical area, including in bone repairing, based on the combination of such materials with biopolymers, as the increased surface area improves the mechanical properties of these new biomaterials and provides more nucleation sites for apatite, increasing their bioactive potential, making this kind of composite great candidates for third-generation tissue engineering [14-16, 9, 17-21, 3, 22].

This study aims to investigate the effects of different compositions $\left(\mathrm{SiO}_{2}-\mathrm{CaO}-\mathrm{P}_{2} \mathrm{O}_{5}\right.$ and $\left.\mathrm{SiO}_{2}-\mathrm{CaO}\right)$ and thermal treatments on the morphology and in vitro bioactivity of BGNPs. As is referred to in the literature, the morphology and size of the bioactive particles can be controlled by the rate of the hydrolysis and condensation reactions [10]. The $\mathrm{pH}$ was therefore also chosen in this work as a parameter to study its influence on the morphology and the size of the bioactive glass particles.

A sol-gel method was previously combined with coprecipitation and applied in this work to different formulation systems in order to obtain nanosized particles [23]. The advantage of combining these materials with biopolymers is also investigated and a composite of chitosan and the BGNPs is developed.

\section{Experimental methods}

\subsection{BG-NP preparation}

To prepare the BG-NPs a protocol based on previous works was followed [24, 25]. The procedure for the ternary BG-NP preparation, with the composition $\mathrm{SiO}_{2}: \mathrm{CaO}: \mathrm{P}_{2} \mathrm{O}_{5}(\mathrm{~mol} \%)=$ $55: 40: 5$, consisted in sequential reagent dissolutions that resulted in hydrolysis and polycondensation reactions. The same procedure with the necessary adaptations was followed to obtain $\mathrm{SiO}_{2}: \mathrm{CaO}(\mathrm{mol} \%)=70: 30$, in which no P precursor was used. Tetraethyl orthosilicate (TEOS, $99.90 \%$ pure) was used as the Si precursor, ammonium phosphate dibasic as the $\mathrm{P}$ precursor, calcium nitrate tetrahydrate $(99 \%)$ as the Ca precursor, citric acid monohydrate (99-100\%) to promote hydrolysis, ethanol absolute, ammonium hydroxide (maximum of $33 \% \mathrm{NH}_{3}$ ) as the gellyfying agent and polyethylene glycol 20000 (PEG) as the surfactant were purchased from SigmaAldrich. In some cases the BG-NPs were sintered at $700^{\circ} \mathrm{C}$, according to the thermogravimetric and differential thermal analysis (TG/DTA) study of dried gels of a similar system performed by Ma et al [26].

\subsection{Chitosan/BG-NPs composite preparation}

The membranes were obtained dissolving chitosan (0.7 wt/vol\%) and BG-NPs (0.3 wt/vol\%) in 2 vol\% acetic acid. The control membranes contain $1 \mathrm{wt} / \mathrm{vol} \%$ of chitosan. After evaporation for several days, the membranes were neutralized in $\mathrm{NaOH} 0.1 \mathrm{M}$, and left to dry.

\subsection{XRD analysis}

$\mathrm{X}$-ray diffraction measurements were performed with a Bruker D8 Discover model operated at $40 \mathrm{kV}$ and $40 \mathrm{~mA}$ using $\mathrm{Cu} \mathrm{K} \alpha$ radiation. The detector was scanned over a range of $2 \theta$ angles from $15^{\circ}$ to $60^{\circ}$ at a step size of $0.04^{\circ}$ and dwell time of $1 \mathrm{~s}$ per step.

\subsection{FTIR spectroscopy analysis}

Fourier-transform infrared (FTIR) spectroscopy analysis was carried out in an IR Prestige 21 Shimadzu spectrometer. The samples were prepared by pressing the BG-NPs with $\mathrm{KBr}$ into a small disc. The FTIR spectra were recorded from 400 to $4400 \mathrm{~cm}^{-1}$ with the resolution of $4 \mathrm{~cm}^{-1}$. Before measurements the powders were dried at $100^{\circ} \mathrm{C}$ overnight to remove any adsorbed molecules.

\subsection{In vitro bioactivity study}

In vitro bioactivity tests were carried out by soaking $10 \mathrm{mg}$ of bioactive glass in $15 \mathrm{ml}$ of SBF (simulated body fluid) solution in the case of BG-NPs powders, and $1 \mathrm{~cm}^{2}$ per $50 \mathrm{ml}$ of SBF in the case of chitosan/BG-NPs composite for zero (control), one, three, five and seven days at $37^{\circ} \mathrm{C}$. Upon removing from $\mathrm{SBF}$, the samples were rinsed with distilled water and left to dry. The SBF was prepared by dissolving $\mathrm{NaCl}, \mathrm{NaHCO}_{3}$, $\mathrm{KCl}, \mathrm{K}_{2} \mathrm{HPO}_{4} \cdot 3 \mathrm{H}_{2} \mathrm{O}, \mathrm{MgCl}_{2} \cdot 6 \mathrm{H}_{2} \mathrm{O}$ and $\mathrm{Na}_{2} \mathrm{SO}_{4}$ in distilled water and buffered with Tris buffer and $\mathrm{HCl}$ to reach a $\mathrm{pH}$ value of 7.4, following the protocol described by Kokubo and Takadama [27]. All materials were purchased from SigmaAldrich.

\subsection{SEM and EDX sample preparation}

To study the surface and the morphology of the samples, a NanoSEM-FEI Nova 200 (FEG/SEM) scanning electron microscope was used. A conductive gold coating was applied to the samples. A Pegasus $\mathrm{X} 4 \mathrm{M}$ instrument was used to perform the EDX experiments at low vacuum and without coating.

\subsection{Cell viability tests}

Cell viability and metabolic activity were determined using the MTS assay. L929 mouse fibroblasts were seeded in a multi-wall plate and nourished with Dulbecco's modified minimum essential medium (D-MEM) supplemented with $10 \%$ fetal bovine serum (FBS) and $1 \%$ antibiotic. The plates were incubated at $37{ }^{\circ} \mathrm{C}$ with $5 \% \mathrm{CO}_{2}$. In the meantime, fluid extracts were obtained by placing in a falcon tube $0.2 \mathrm{~g}$ of sterile BG-NPs per $\mathrm{ml}$ of culture medium. After $24 \mathrm{~h}$ under stirring at $37^{\circ} \mathrm{C}$, the media, with different extracts from each sample, were filtered and applied, as the nourishment medium, to the plates containing the cells previously seeded. The cultures were then incubated at $37^{\circ} \mathrm{C}$ for one, three and seven days. The culture media was replaced on the third day. The MTS (3-(4,5-dimethylthiazol-2-yl)-5(3-carboxymethoxyphenyl)-2-(4-sulfophenyl)-2H-tetrazolium) 
test was performed to determine the cytotoxicity of the BGNPs. In this assay, the tetrazolium compound is reduced by the viable cell's mitochondria into a water-soluble brown formazan product. The relative viability $(\%)$ of the cells was determined by comparing the obtained results with cells grown without BG-NP extracts that were used as a positive control of cell viability. Latex was considered to be a negative control of cellular viability. After each time point (one, three and seven days of culture), the MTS test was performed to assess the metabolic activity of the cells in contact with the BG-NP extracts. For this assay, an MTS solution was prepared by using a 1:5 ratio of MTS reagent and D-MEM culture medium (without phenol red or FBS). After removal of the fluid extracts and washing with PBS, $100 \mu 1$ of MTS reagent was added to each sample followed by a $3 \mathrm{~h}$ incubation period at $37^{\circ} \mathrm{C}$. Finally, the cell supernatant of each sample was removed to another plate and their optical density (OD) was read at $490 \mathrm{~nm}$ on a microplate reader (Synergy HT, Bio-Tek Instruments). The values of optical density are directly proportional to the quantity of formazan product and thereby to the number of living cells analyzed. All cytotoxicity tests were conducted by using five replicates.

\section{Results and discussion}

BG-NPs were obtained by the sol-gel method. This is a very straightforward method to produce bioactive glasses; nevertheless, it still requires some important steps such as the addition of a basic catalyst to promote precipitation of the particulate gel and the reduction of the gelation time [28, 29], as well as a heat treatment to incorporate calcium and remove organic residues [10]. Therefore, besides the study of the formulation's influence, the $\mathrm{pH}$ resulting from the addition of different amounts of $\mathrm{NH}_{4} \mathrm{OH}$ as the basic catalyst and the differences between samples heat-treated and non-heat-treated were also analyzed.

\subsection{Chemical composition}

3.1.1. X-ray diffraction (XRD). XRD patterns of the studied samples are shown in figure 1. As is well known, glass is an amorphous inorganic material with no detectable diffraction maxima. Therefore, it is expected that the bioactive glass diffractograms will reflect the amorphous nature of this material. Indeed, XRD spectra of both the binary and ternary system prepared at $\mathrm{pH} 11.5$ and after thermal treatment, respectively figures $1(\mathrm{~d})$ and $(\mathrm{h})$, exhibit a broad dispersive band, indicating the amorphous nature of the bioactive glass.

Before being submitted to the thermal treatment, the diffractograms present two parasite lines $\left(19^{\circ}\right.$ and $\left.24^{\circ}\right)$ reported in the literature as being associated with $\mathrm{Si}$ [30]. After the thermal treatment process, the lines disappear.

Hong et al concluded that the crystallinity of bioactive glass ceramic nanoparticles obtained with the same preparation conditions could increase with increasing phosphate content [31]. However, comparing the diffractograms in figure 1 of binary (with no P) and ternary (with 5\% P) samples obtained at different $\mathrm{pH}(9$ and 11.5$)$ and temperatures $\left(0\right.$ and $\left.700^{\circ} \mathrm{C}\right)$, one (h)

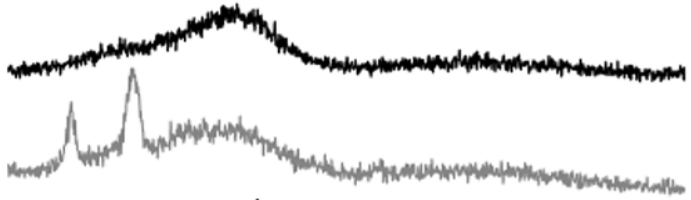

(f)

(e)

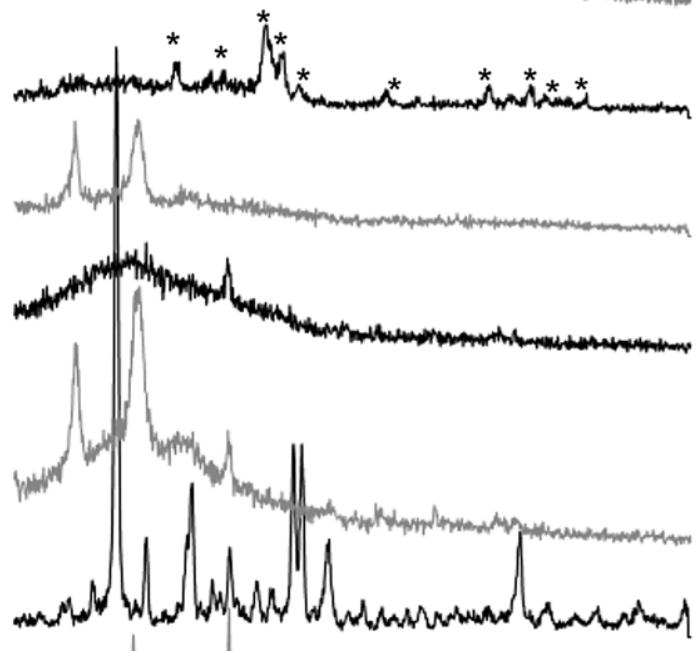

(a)

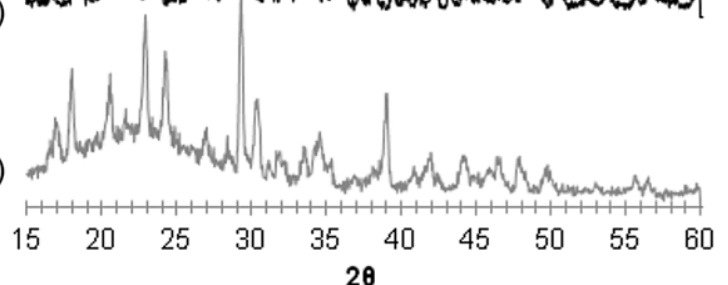

Figure 1. XRD spectra of raw and thermally treated BG-NPs produced at different $\mathrm{pH}$ and formulations: binary $\mathrm{pH} 9$ (a) $0^{\circ} \mathrm{C}$, (b) $700^{\circ} \mathrm{C}$; binary pH 11.5 (c) $0{ }^{\circ} \mathrm{C}$, (d) $700^{\circ} \mathrm{C}$; ternary pH 9 (e) $0{ }^{\circ} \mathrm{C}$, (f) $700^{\circ} \mathrm{C}$; ternary $\mathrm{pH} 11.5(\mathrm{~g}) 0^{\circ} \mathrm{C}$, (h) $700^{\circ} \mathrm{C}$ and hydroxyapatite peaks are indicated $(*)$.

can conclude that the major differences in crystallinity arise from the $\mathrm{pH}$ of preparation. The spectra do not reflect the composition of the system in terms of the presence or absence of $\mathrm{P}$. However, the $\mathrm{pH}$ of preparation seems to be the most important factor setting the amorphous or crystalline character of the material after the thermal treatment. When working at $\mathrm{pH} \mathrm{9,} \mathrm{the} \mathrm{sintered} \mathrm{sample} \mathrm{spectrum} \mathrm{from} \mathrm{both} \mathrm{the} \mathrm{binary,}$ figures 1(a) and (b), and ternary, figures 1(e) and (f), systems reflect the existence of crystalline phases, as some diffraction maxima can be observed. Comparing the ternary samples after thermal treatment (figures 1(f) $-\mathrm{pH} 9$ and (h) $-\mathrm{pH} 11.5$ ), the main difference is related to the crystallinity. With respect to the ternary sample prepared at $\mathrm{pH} \mathrm{9,} \mathrm{figure} \mathrm{1(f),} \mathrm{the} \mathrm{thermal}$ treatment process seems to lead to the hydroxyapatite typical diffractogram. The main lines are typical phosphate crystal peaks showing the presence of hydroxyapatite, which exhibits well-defined diffraction maxima at $2 \theta=25.9^{\circ}, 29^{\circ}, 31.8^{\circ}$, $32.2^{\circ}, 32.9^{\circ}, 34^{\circ}, 39.8^{\circ}, 46.7^{\circ}, 49.5^{\circ}, 50.5^{\circ}$ and $53.1^{\circ}$. The apatite peaks' presence can be explained based on two different reasons. The first one is that, in the aqueous environment of the sol-gel process, precipitation of hydroxyapatite can occur from the amorphous structure of silica-based bioactive glasses [32]. However, it could also be the case that the thermal treatment temperature was excessively high and therefore 
passing the value of minimum stabilization temperature that ensures a maximum of bioactivity before the crystallization of the material. A higher crystallinity has a lower dissolution rate which has a direct detrimental effect on bioactivity [10]. On the other hand, the sample prepared at $\mathrm{pH} 11.5$, figure 1(h), presents an amorphous spectrum after thermal treatment very similar to the one associated with the commercial Bioglass ${ }^{\circledR}$, as only the characteristic amorphous band at low angles is visible. Crystallization of bioactive glasses decreases the level of bioactivity and even turns a bioactive glass into a bioinert material [31]. It appears to be the case of the binary samples prepared at $\mathrm{pH} 9$ (figures 1(a) and (b)), with a considerable amount of peaks with very high crystallinity, as the size of the peaks can be related to their crystallinity. These samples are the ones exhibiting the lower bioactivity as will be confirmed further in this study.

In all samples except for the sintered ternary powders prepared at $\mathrm{pH} 11.5$, figure $1(\mathrm{~h})$, the thermal stabilization leads to a more crystalline sample, which may happen due to the small size of the particles, which, having a higher specific surface area, also have higher driving forces for nucleation in crystals [10]. Samples of the ternary system prepared at $\mathrm{pH} 11.5$, figures $1(\mathrm{~g})$ and $(\mathrm{h})$, form a broad band centered at a $2 \theta$ value of $30^{\circ}$ that corresponds to the wollastonite $\left(\mathrm{CaSiO}_{3}\right)$ phase. Labbaf et al claim that thermal treatment temperatures should be the lowest value able to retain the particles in the amorphous state. As a temperature of $700^{\circ} \mathrm{C}$ was used, and the amorphous shape was kept, this seems to be the ideal stabilization temperature before reaching a wollastonite crystalline phase that would decrease the bioactive potential of the BG-NPs. Thermal treatment is always a necessary step because it is essential to incorporate calcium at approximately $450{ }^{\circ} \mathrm{C}$, to remove the organic phase at $500^{\circ} \mathrm{C}$ and to reduce silanol groups from the glass surface and nitrate by-products from the glass network at $600{ }^{\circ} \mathrm{C}$ [10].

\subsubsection{FTIR measurements. The FTIR spectra of the} produced BG-NPs are presented in figure 2. Silicate absorption bands are observed in all spectra, assigned to the peaks 1085 , 800 and $464 \mathrm{~cm}^{-1}$, respectively: asymmetric stretching mode, symmetric stretching vibration and rocking vibration of $\mathrm{Si}-\mathrm{O}-$ Si [26].

In the sintered ternary system sample prepared at $\mathrm{pH}$, figure 2(f), the heating treatment at $700{ }^{\circ} \mathrm{C}$ is shown by two narrow peaks at 580 and $600 \mathrm{~cm}^{-1}$, indicating a $\mathrm{P}-\mathrm{O}$ bending vibration due to the presence of a crystalline calcium phosphate (apatite-like) phase [26]. These twin bands merge into a weak band in the case of amorphous glass, figures 2(e), (g) and (h). This is in accordance with the XRD data. Moreover, the Prelated peaks do not appear in the binary spectra, figures 2(a)(d), since they do not include $\mathrm{P}$ in their formulation. In the case of ternary system samples, figures $2(\mathrm{e})-(\mathrm{h})$, peaks at 1045 and $1090 \mathrm{~cm}^{-1}$ are also assigned to the $\mathrm{P}-\mathrm{O}$ bond although masked by the broad silicate band [31]. At $950 \mathrm{~cm}^{-1}$ one can confirm the $\mathrm{Ca}$ presence due to the peak related to $\mathrm{Si}-\mathrm{O}-\mathrm{Ca}$ bonds containing non-bridging oxygen [26]. The $1630 \mathrm{~cm}^{-1}$ is assigned to the $\mathrm{OH}$ group due to residual $\mathrm{H}_{2} \mathrm{O}$ absorbed in the BG-NP [33]. Bands related to the presence

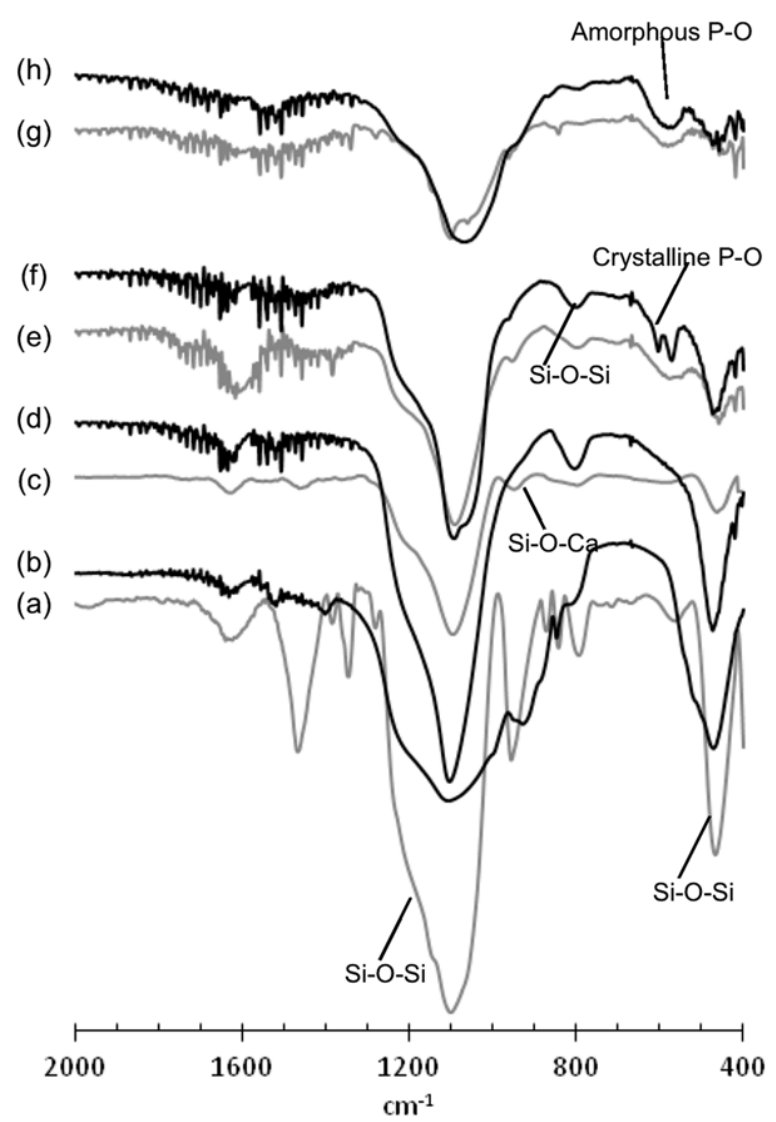

Figure 2. Infrared spectra of raw and thermally treated BG-NPs: binary pH 9 (a) $0{ }^{\circ} \mathrm{C}$, (b) $700^{\circ} \mathrm{C}$; binary pH 11.5 (c) $0{ }^{\circ} \mathrm{C}$, (d) $700{ }^{\circ} \mathrm{C}$; ternary $\mathrm{pH} 9$ (e) $0^{\circ} \mathrm{C}$, (f) $700^{\circ} \mathrm{C}$ and ternary $\mathrm{pH} 11.5$ (g) $0^{\circ} \mathrm{C}$, (h) $700{ }^{\circ} \mathrm{C}$

of the calcium precursor $\mathrm{Ca}\left(\mathrm{NO}_{3}\right)_{2}, 1400-1300 \mathrm{~cm}^{-1}(\mathrm{~N}=\mathrm{O}$ bend) and $1600-1500 \mathrm{~cm}^{-1}(\mathrm{~N}=\mathrm{O}$ stretch $)$ disappear after the thermal treatment, confirming the decomposition of the nitrate $\mathrm{Ca}\left(\mathrm{NO}_{3}\right)_{2}$ at $700{ }^{\circ} \mathrm{C}$, especially the vibrations of ionic $\left(\mathrm{NO}_{3}\right)^{-}$at $1380 \mathrm{~cm}^{-1}$ [33]. These bands are more evident in the binary $\mathrm{pH} 9-0^{\circ} \mathrm{C}$, figure 2 (a) and tend to attenuate after thermal treatment. Also in figure $2(\mathrm{a})$, the $1630 \mathrm{~cm}^{-1}$ stretching vibration of the $\mathrm{H}-\mathrm{O}$ bond, related to water is more evident. The $1340 \mathrm{~cm}^{-1}$ sharp peak could also be due to the presence of water as it is assigned to $\mathrm{OH}$ free groups. The $1460 \mathrm{~cm}^{-1}$ could be assigned to a carbonate absorption band, due to the carbonate existing in the lattice of the binary $\mathrm{pH} 9$ BG-NPs, as a result of $\mathrm{CO}_{2}$ dissolution from the atmosphere during the sol-gel procedure [34]. After thermal treatment this band disappears.

3.1.3. Energy dispersive $x$-ray (EDX) analysis. Through energy dispersive $\mathrm{x}$-ray (EDX) analysis, it was possible to quantify the final ratios of the binary and ternary compositions in atomic percentage (at.\%). The results are presented in table 1 . The measured values present deviations regarding the initial formulations. As can be observed in the table, the particles produced at $\mathrm{pH} 9$ have the right original proportions of $\mathrm{Si}$ and $\mathrm{Ca}$ in the binary case, but in the ternary system only $\mathrm{Si}$ is at the original percentage and $\mathrm{P}$ is three times higher, 
Table 1. EDX quantification (at.\%).

\begin{tabular}{|c|c|c|c|c|c|c|c|c|}
\hline \multirow[b]{3}{*}{ at. $\%$} & \multicolumn{4}{|c|}{ Binary } & \multicolumn{4}{|c|}{ Ternary } \\
\hline & \multicolumn{2}{|c|}{ pH 9} & \multicolumn{2}{|c|}{ pH 11.5} & \multicolumn{2}{|c|}{ pH 9} & \multicolumn{2}{|c|}{$\mathrm{pH} 11.5$} \\
\hline & $0{ }^{\circ} \mathrm{C}$ & $700^{\circ} \mathrm{C}$ & $0{ }^{\circ} \mathrm{C}$ & $700^{\circ} \mathrm{C}$ & $0{ }^{\circ} \mathrm{C}$ & $700^{\circ} \mathrm{C}$ & $0{ }^{\circ} \mathrm{C}$ & $700^{\circ} \mathrm{C}$ \\
\hline $\mathrm{Si}$ & 70.24 & 69.15 & 82.00 & 81.53 & 52.63 & 55.30 & 33.46 & 35.31 \\
\hline $\mathrm{P}$ & 0 & 0 & 0 & 0 & 14.62 & 15.01 & 20.40 & 21.87 \\
\hline $\mathrm{Ca}$ & 29.76 & 30.85 & 18 & 18.47 & 32.75 & 29.69 & 46.14 & 42.81 \\
\hline
\end{tabular}

and consequently $\mathrm{Ca}$ is $15 \%$ below the original percentage. At $\mathrm{pH} 11.5 \mathrm{Si}$ is above the initial value in the binary system (and $\mathrm{Ca}$ below). On the other hand, in the ternary system, $\mathrm{Si}$ is almost $20 \%$ below the original set value and $\mathrm{Ca}$ remains in the right proportion, $\mathrm{P}$ being four times higher. The reason for these differences may be the removal of free calcium ions during the washing step. Indeed, in the sol stage, almost $100 \%$ of $\mathrm{Ca}$ dissolves in the pore liquor as calcium nitrate, and it will only deposit in the drying step. Therefore, the final composition of bioactive glass can be changed if the pore liquor is washed before drying, removing the calcium that was not incorporated in the silica or phosphoric gel network [10, 34]. This fact would explain the variation in values obtained, as the experimental procedure followed in this work includes a washing step, necessary to remove the ammonia from the gel.

\subsection{Surface analysis}

Surface analysis was performed by scanning electron microscopy (SEM) observation. The samples were previously coated with a thin gold layer. The differences in the BGNPs both in size and morphology were analyzed between the different batches of BG-NPs produced. At $\mathrm{pH}$ 9, figures 3(a), (b) and (e), (f), the size of the particles is more heterogeneous, especially in the ternary case, figures $3(\mathrm{e})$ and (f), where the sizes could vary in the range 50-200 nm. The particles produced at $\mathrm{pH} 11.5$, figures $3(\mathrm{c})$, (d) and $(\mathrm{g})$, (h), have sizes below $40 \mathrm{~nm}$.

Regarding the effect of calcination in the morphologies of the binary and ternary systems, at $\mathrm{pH} 9$ particles appear to be melted and more aggregated and at $\mathrm{pH} 11.5$, besides the aggregation, there is also a decrease in the particles size. This consequence is not evident in the ternary particles produced under the same conditions. It is known that temperatures higher than $700^{\circ} \mathrm{C}$, in the ternary system, have the effect of melting and sintering the particles in large aggregates [23]. A shorter temperature of calcination is thought more suitable to apply in binary systems, in order to avoid the fusion of the particles and their densification due to the sintering effect.

In all cases the particles are round shaped. Labbaf et al claim that the spherical shape is in part due to the use of ammonium hydroxide as catalyst, although the morphology and size can be as well controlled by the rate of the hydrolysis and condensation reactions. Even though it is know that, when using a base catalyst to control the condensation reaction the particles do not assemble, some agglomeration is observed. However, the catalyst chosen prevents them fusing together during thermal treatment [10].

\subsection{Cytotoxicity tests of the BG-NPs}

The BG-NP effect on cell metabolic activity was assessed by seeding L929 cells with their leachables. Figure 4 shows the cell's viability evaluated by carrying out the MTS test. A slight decline in the cellular metabolic activity was verified from the first to the third day in all samples, the decrease being more relevant in sample (a). The mentioned decrease was followed by a viability increase from day three to day seven. These results suggest that the cell's metabolism is being influenced by the ions present in the leachables, as sample (a) showed the presence of more chemical species in FTIR analysis (see figure 2) and, as a consequence, it has the most evident decrease in the third day viability. Nevertheless, the interactions between the cells and the BG-NP leachables do not affect significantly their viability, as it increases again towards the seventh day of culturing.

The cell's behavior throughout the study time proves the non-toxicity of the materials produced at different $\mathrm{pH}$ and also before and after thermal treatment. Therefore, high biocompatibility of the materials is ensured in all of the studied conditions.

\subsection{In vitro bioactivity test of the $B G-N P S$}

It is commonly accepted that the bioactivity of glasses relies on their ability to induce hydroxyapatite formation in a physiological environment, such as simulated body fluid (SBF) that reproduces the human plasma by having similar $\mathrm{pH}$ and ionic composition. In this environment, the bioactive glasses will release ions and form silanol groups on its surface that will act as a nucleating agent for a hydroxyapatite layer [35]. Being an interface-driven phenomenon, bioactivity will depend on parameters such as surface charge, composition, structure and morphology [36]. In fact, these parameters will influence the dissolution rate of the materials, whose ideal ionic concentrations will define the ability to stimulate cellular proliferation and differentiation [2].

3.4.1. X-ray diffraction (XRD). Figure 5 shows the XRD spectra of the BG-NPs in all of the studied conditions after soaking in SBF for seven days. In the nonsintered samples of the binary systems, both $\mathrm{pH} 9$ and 11.5, figures 5(a) and (c), just one to three of the major diffraction peaks in the spectra can be interpreted as hydroxyapatite, as a result of being soaked in SBF after seven days. In contrast, the sintered binary samples, figures $5(\mathrm{~b})$ and (d), especially the one prepared at $\mathrm{pH} 11.5$, figure 5(d), have several peaks related to hydroxyapatite regarding day seven of SBF soaking. 


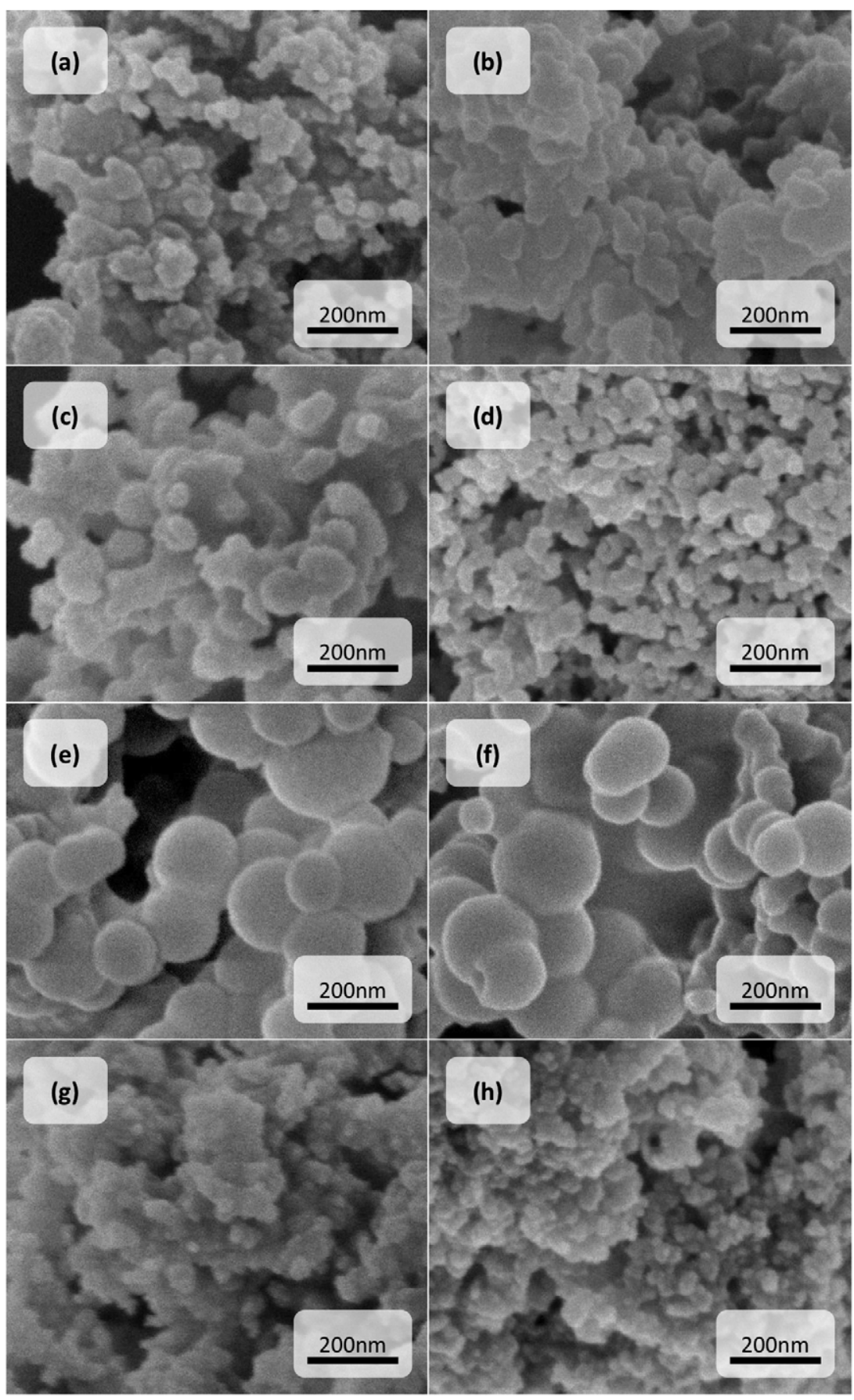

Figure 3. SEM of raw and thermally treated BG-NPs: binary pH 9 (a) $0{ }^{\circ} \mathrm{C}$, (b) $700{ }^{\circ} \mathrm{C}$; binary $\mathrm{pH} 11.5$ (c) $0{ }^{\circ} \mathrm{C}$, (d) $700{ }^{\circ} \mathrm{C}$; ternary pH 9 (e) $0{ }^{\circ} \mathrm{C}$, (f) $700^{\circ} \mathrm{C}$ and ternary $\mathrm{pH} 11.5(\mathrm{~g}) 0^{\circ} \mathrm{C}$, (h) $700^{\circ} \mathrm{C}$.

In the case of the ternary system without thermal treatment, figures $5(\mathrm{e})$ and $(\mathrm{g})$, the particles after seven days present an apatitic layer at their surface, with several peaks of the spectrum matching the ones of hydroxyapatite. It is possible to conclude that, in each system (binary or ternary), at $\mathrm{pH} 11.5$, figures $5(\mathrm{e})-(\mathrm{h})$, there are more peaks related to hydroxyapatite than in the samples produced at $\mathrm{pH}$ 9, figures 5(a)-(d). Regarding the temperature, the heat treatment at $700{ }^{\circ} \mathrm{C}$ is conducive to better bioactivity than the non-heat-treated samples, as the diffraction angles of the peaks after soaking in SBF match the reference x-ray spectra of hydroxyapatite.
Considering the formulation of the BG-NPs, the ternary system exhibits a layer of pure hydroxyapatite after seven days of immersion, when treated at $700^{\circ} \mathrm{C}$, at both pHs, figures 5(f) and (h). One can conclude that the ternary formulation has better bioactivity results than the binary one, and that thermal treatment has an important role in promoting the mineralization ability, regardless of the $\mathrm{pH}$ of preparation in this study.

3.4.2. Scanning electron microscopy (SEM). Bioactivity can be confirmed by observing the development of a 


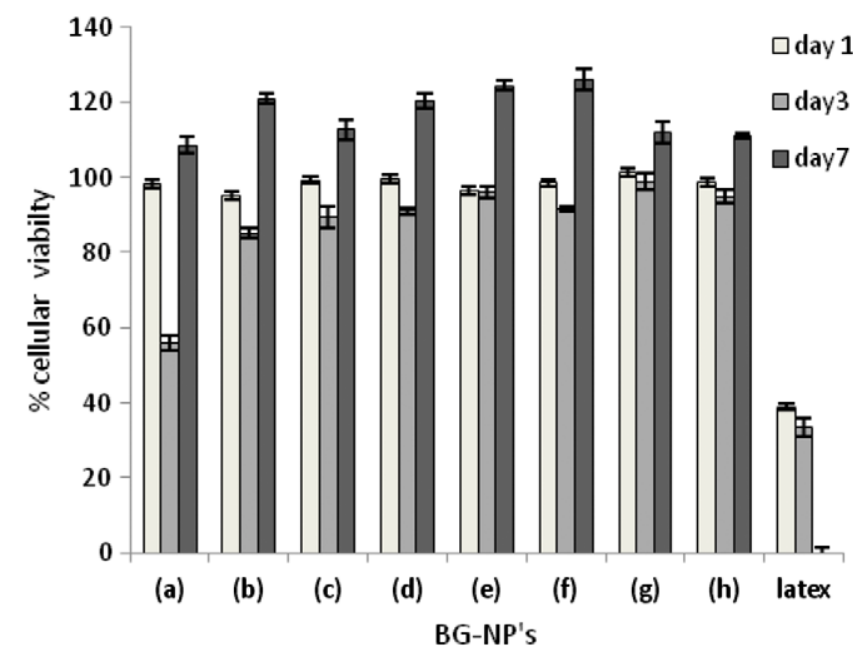

Figure 4. Cytotoxicity test results of raw and thermally treated BG-NPs over three time points (one, three and seven days): binary pH 9 (a) $0{ }^{\circ} \mathrm{C}$, (b) $700{ }^{\circ} \mathrm{C}$; binary pH 11.5 (c) $0{ }^{\circ} \mathrm{C}$, (d) $700{ }^{\circ} \mathrm{C}$; ternary pH 9 (e) $0{ }^{\circ} \mathrm{C}$, (f) $700^{\circ} \mathrm{C}$; ternary pH $11.5(\mathrm{~g}) 0^{\circ} \mathrm{C}$, (h) $700^{\circ} \mathrm{C}$ and all data were expressed as mean \pm standard deviation for $n=5$.

needle-like apatite layer, forming cauliflower-like clusters on the surface of the particles, namely hydroxyapatite $\left(\mathrm{Ca}_{10}\left(\mathrm{PO}_{4}\right)_{6-x}\left(\mathrm{HPO}_{4}\right)_{x}(\mathrm{OH})_{2-x}\right)$, the main mineral constituent of bone [37].

Observing the images in figure 6, obtained in the SEM study of the bioactivity of BG-NP powders, one can conclude that the amount of apatitic crystals at the surface of the samples increases when the $\mathrm{pH}$ is 11.5 instead of 9 , and when the formulation is of a ternary system instead of binary. Indeed, after seven days of soaking the samples in SBF, it is possible to observe that the condition with the richer apatitic film is the one corresponding to the ternary system produced at $\mathrm{pH} 11.5$ both at $0{ }^{\circ} \mathrm{C}$ and sintered at $700{ }^{\circ} \mathrm{C}$, indicating the best bioactivity in a qualitative evaluation, figures $6(\mathrm{~g})$ and $(\mathrm{h})$.

The XRD data previously presented support these conclusions and confirm that the calcified film is related to hydroxyapatite.

3.4.3. Energy dispersive $x$-ray analysis (EDX). The results obtained by SEM were also confirmed by EDX analysis that allowed the following of the elemental evolution throughout the time period of study. After soaking in SBF, the expected behavior of a bioactive material containing $\mathrm{Si}$ and $\mathrm{Ca}$ (as in the case of BG-NPs) is the rising of $\mathrm{Si}$ accompanied by the decrease of $\mathrm{Ca}$ in the first stage, due to the exchange of the last elements with $\mathrm{H}^{+}$and $\mathrm{H}_{3} \mathrm{O}^{+}$from the environment. After this first step, disruption of the glass network occurs by hydrolysis and as $\mathrm{Si}-\mathrm{O}-\mathrm{Si}$ bridges break, during which soluble silica is lost to the solution in the form of $\mathrm{Si}(\mathrm{OH})_{4}$ leading to the formation of silanol groups $(\mathrm{Si}-\mathrm{OH})$ at the BG-NP/solution interface. The $\mathrm{OH}^{-}$groups from silanol will attract $\mathrm{Ca}^{2+}$ and $\mathrm{PO}_{4}^{3-}$ from the surrounding media and precipitation occurs. An amorphous calcium phosphate layer begins to grow on the surface of the sample, and the $\mathrm{Ca}$ and $\mathrm{P}$ values increase. In contrast, $\mathrm{Si}$ content decreases (h)

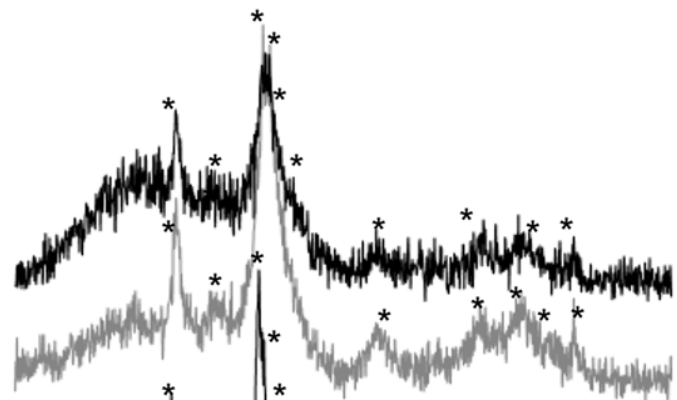

(f)

(e)

(d)

(c)

(b)

(a)

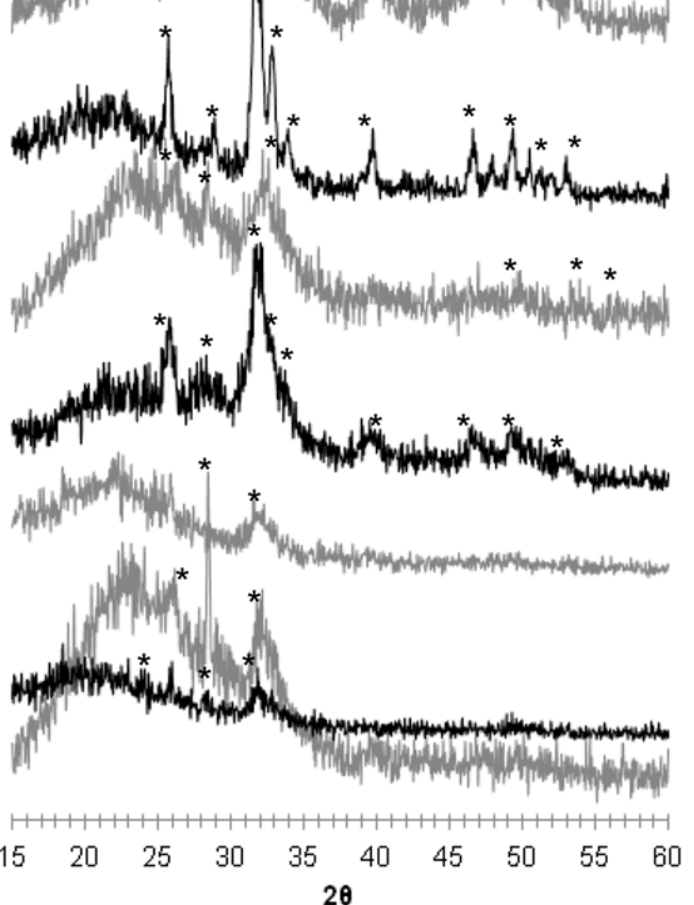

Figure 5. XRD spectra of raw and thermally treated BG-NPs produced at different $\mathrm{pH}$ and formulations after seven days of immersion in SBF: binary $\mathrm{pH} 9$ (a) $0{ }^{\circ} \mathrm{C}$, (b) $700^{\circ} \mathrm{C}$; binary $\mathrm{pH} 11.5$ (c) $0{ }^{\circ} \mathrm{C}$, (d) $700{ }^{\circ} \mathrm{C}$; ternary $\mathrm{pH} 9$ (e) $0{ }^{\circ} \mathrm{C}$, (f) $700^{\circ} \mathrm{C}$; ternary pH 11.5 (g) $0{ }^{\circ} \mathrm{C}$, (h) $700^{\circ} \mathrm{C}$ and hydroxyapatite peaks are indicated $(*)$.

proportionally. The incorporation of $\mathrm{OH}^{-}$and $\mathrm{CO}_{3}^{2-}$ anions from the solution leads to the final step of mineralization which is the formation of a crystalline hydroxyapatite layer [38].

In fact, in all systems as the study proceeds, the Si content decreases and the $\mathrm{Ca}$ and $\mathrm{P}$ increase. The $\mathrm{P}$ is taken out from the SBF in the case of the binary systems, see figures 7(a) and (c). This strengthens the indication of the development of apatite material onto the BG-NP surfaces.

This behavior varies in time according to the bioactive potential of each sample. In the case of the binary and ternary systems prepared at $\mathrm{pH}$ 9, figures 7(a) and (b), respectively, the effect of the ion exchange is more significant after the fifth day of the study, when Si begins to decrease and the $\mathrm{Ca}$ and $\mathrm{P}$ values become higher.

In the binary system produced at $\mathrm{pH} 11.5$, figure 7 (c), the apatite begins to develop earlier, after three days of immersion in SBF. In the case of the ternary system $\left(\mathrm{SiO}_{2}-\mathrm{CaO}-\mathrm{P}_{2} \mathrm{O}_{5}\right)$ produced at the same $\mathrm{pH}$, the bioactivity character just needs one day to express itself, figure 7(d). This last system is then the most bioactive one. 


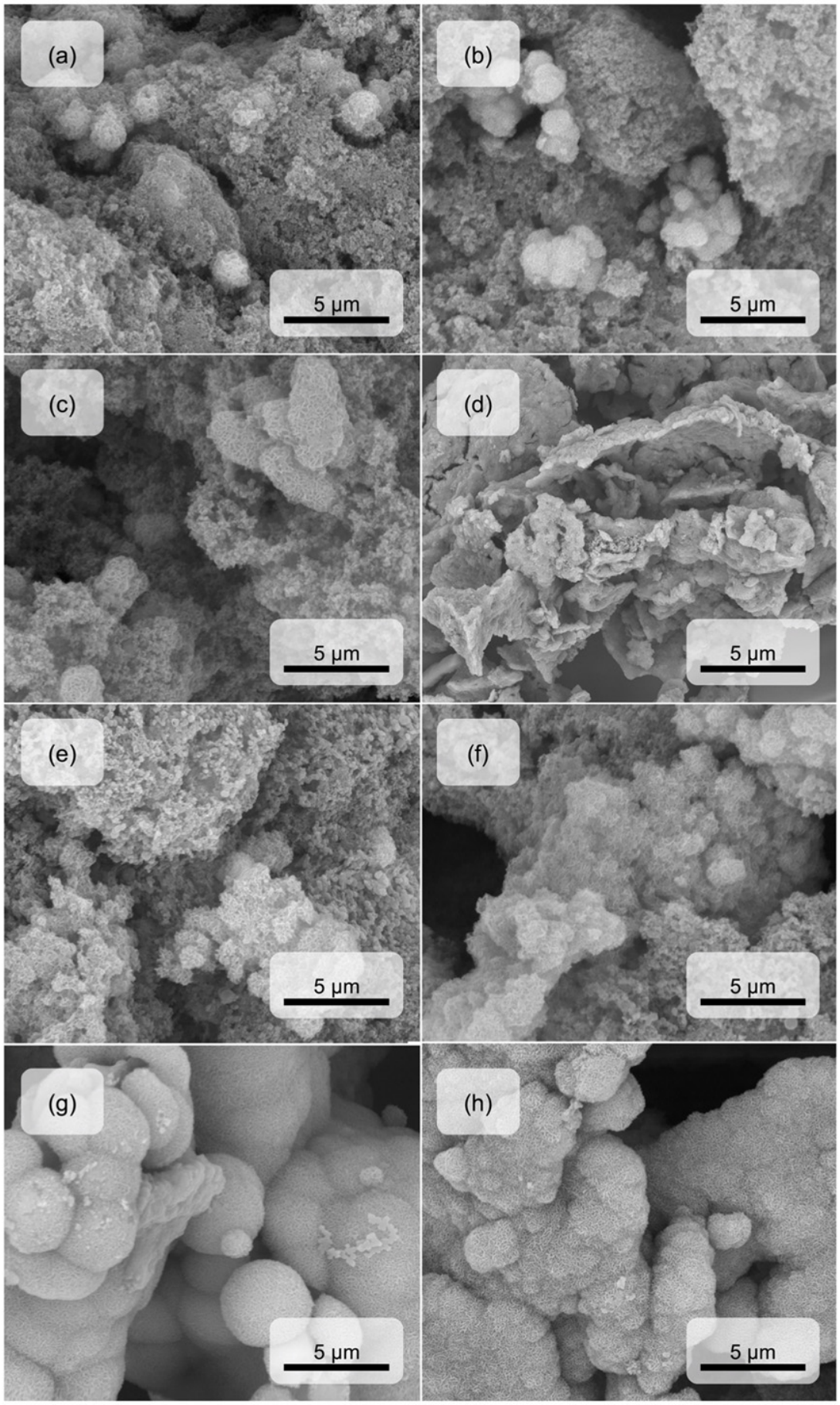

Figure 6. SEM images of the BG-NPS after seven days in SBF, revealing cauliflower-like apatite clusters on their surface: binary pH 9 (a) $0{ }^{\circ} \mathrm{C}$, (b) $700{ }^{\circ} \mathrm{C}$; ternary $\mathrm{pH} 9$ (c) $0{ }^{\circ} \mathrm{C}$, (d) $700^{\circ} \mathrm{C}$; binary pH 11.5 (e) $0{ }^{\circ} \mathrm{C}$, (f) $700{ }^{\circ} \mathrm{C}$ and ternary pH 11.5 (g) $0{ }^{\circ} \mathrm{C}$, (h) $700^{\circ} \mathrm{C}$.

Regarding the influence of the BG-NP formulation over the bioactive ability of these materials, some facts have to be considered. First, the ability to bond with bone has been shown to depend largely on the silica $\left(\mathrm{SiO}_{2}\right)$ content. As the silica content of the glass increases, the dissolution rate of the apatite layer becomes slow and the bone-bonding ability of the materials decreases. A glass with a content of more than $60 \mathrm{wt} \%$ silica has a dramatic decrease in its bioactivity [38]. Moreover, the BG-NPs with a higher percentage of $\mathrm{Ca}$ are expected to be more prone to dissolution than the ones with higher amounts of $\mathrm{Si}$ in aqueous environments, since calcium disrupts the silica network, reducing its network connectivity (mean number of bridging $-\mathrm{Si}-\mathrm{O}-\mathrm{Si}-$ bonds per silicon atom) and therefore its stability in solution $[10,39]$. Both these facts could justify the reason why samples from binary systems have an inferior bioactivity over the ternary ones.

One can conclude that, at the lower $\mathrm{pH}(9)$, the obtained particles are more crystalline which was previously referred to 

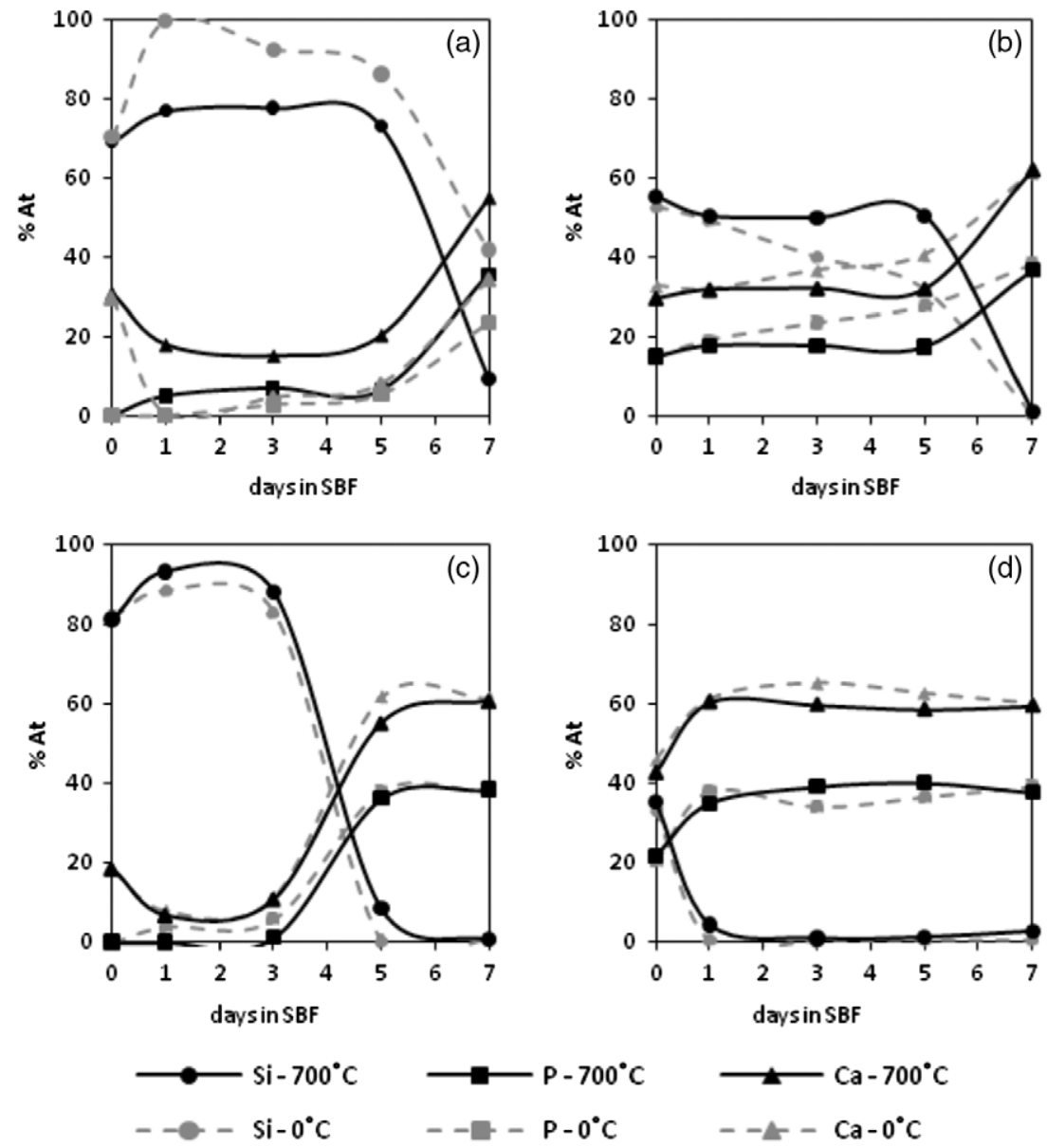

Figure 7. EDX study of the bioactivity of the BG-NPs prepared in different conditions at zero, one, three, five and seven days. (a) Binary $\mathrm{pH} 9$ at 0 and $700^{\circ} \mathrm{C}$, (b) ternary $\mathrm{pH} 9$ at 0 and $700^{\circ} \mathrm{C}$, (c) binary $\mathrm{pH} 11.5$ at 0 and $700^{\circ} \mathrm{C}$ and (d) ternary pH 11.5 at 0 and $700^{\circ} \mathrm{C}$.

as a drawback in setting the bioactive potential, as it lowers the dissolution rate to ineffective values. This fact would explain why the ternary system at $\mathrm{pH} 11.5$ is more bioactive than at $\mathrm{pH} 9$.

In this study, thermal treatment did not have an influence on setting the bioactive potential of the BG-NPs. The differences obtained in the atomic percentages throughout the days of the study were not significant when the samples had been sintered, regardless of the formulation of the particles, although thermal treatment is important to retain the $\mathrm{Ca}$ in the glass network, which is a crucial element for a successful mineralization.

\subsection{Chitosan/BG-NP composite development}

Composites found in nature contain an inorganic phase, with at least one nanometric dimension embedded in an organic matrix, usually assembled in a complex and hierarchical structure [40].

Biomimetic osteoconductive nanocomposites may be obtained by combining bioactive glass/ceramics with a polymeric matrix [22]. In order to mimic this natural structure, the most bioactive powders (ternary, $\mathrm{pH} 11.5,700^{\circ} \mathrm{C}$ ) were applied in the development of chitosan membranes containing BG-NPs dispersed in the polymer. The membranes were obtained by solvent casting of a solution containing chitosan $(0.7 \mathrm{wt} / \mathrm{vol} \%)$ and BG-NPs $(0.3 \mathrm{wt} / \mathrm{vol} \%)$.

Chitosan is an excellent biocompatible polymer, although, by itself, it is not capable of reacting within the physiological fluids in order to develop apatite crystals and bond to the bone, figure 8(a). In this study, BG-NPs were applied in the formation of a composite formed by the polymer and the glass powders in order to produce a bioactive composite that allies the remarkable mechanical and processability properties of chitosan to the mineralization induction ability of BGNPs. The nanosize of the particles allows a large dispersion in the polymer as can be observed in figure 8(b), showing a uniform membrane surface. After seven days of immersion in SBF, a dense apatite layer is formed at the surface of the composite (figure $8(\mathrm{c})$ ). The thickness of the apatitic film can be observed because the polymeric membrane shrinks upon drying and the apatite layer breaks (figure $8(\mathrm{~d})$ ). This profile view allows us to estimate the reaction layer thickness as $2 \mu \mathrm{m}$ approximately, having an average thickness of the membrane of $47 \mu \mathrm{m}$. In contrast, the pure chitosan membrane does not present any bioactive character as, after seven days immersion in SBF, no apatite layer was formed at its surface, proving that this ability is caused by the BG-NPs. It was proved then that one can successfully ally the mineralization induction ability of the BG-NPs with the mechanical advantages of 


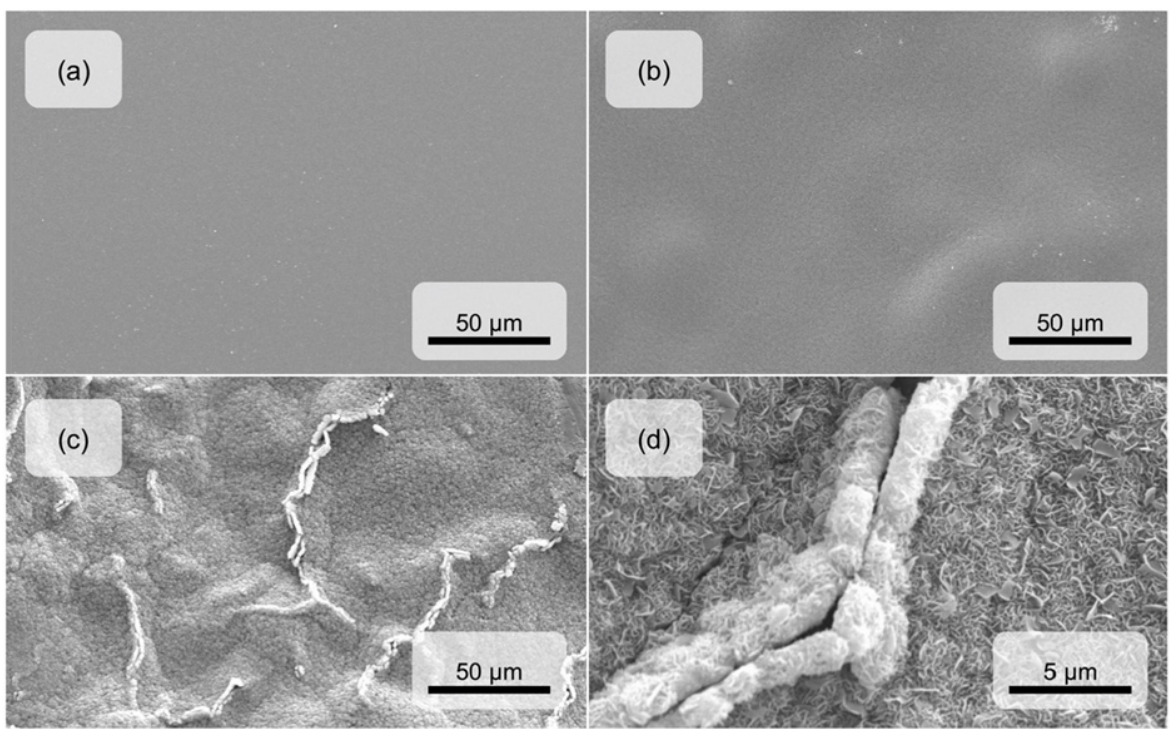

Figure 8. SEM images of the (a) pure chitosan membrane after seven days in SBF; (b) composite of $0.7 \mathrm{wt} / \mathrm{vol} \% \mathrm{chitosan}$ and $0.3 \mathrm{wt} / \mathrm{vol} \%$ BG-NPS (control = zero days in SBF); (c) composite of $0.7 \mathrm{wt} / \mathrm{vol} \%$ chitosan and $0.3 \mathrm{wt} / \mathrm{vol} \%$ BG-NPS after seven days in SBF and (d) composite of $0.7 \mathrm{wt} \%$ chitosan and $0.3 \mathrm{wt} \%$ BG-NPS after seven days in SBF at a higher magnification.

the chitosan biopolymer, producing a nanocomposite with potential applications in bone tissue engineering or in guided tissue regeneration.

\section{Conclusions}

In this work, new bioactive glass nanoparticles based on the $\mathrm{SiO}_{2}-\mathrm{CaO}-\mathrm{P}_{2} \mathrm{O}_{5}$ and $\mathrm{SiO}_{2}-\mathrm{CaO}$ systems were prepared using a sol-gel method. Round shaped particles with sizes below 50 $\mathrm{nm}$ were achieved within the samples produced at $\mathrm{pH}$ 11.5.

The sol-gel BG-NPs obtained in this work, when immersed in SBF, proved the ability to induce mineralization, having the desired characteristics of biomaterials used in bone tissue engineering, i.e. bone bonding and biodegradability. These two properties are highly desirable at, respectively, early and late stages of post-implantation.

The best bioactivity results are from by the samples prepared as a ternary system $\left(\mathrm{SiO}_{2}-\mathrm{CaO}-\mathrm{P}_{2} \mathrm{O}_{5}\right)$. With the obtained data, one can conclude that the thermal treatment at $700^{\circ} \mathrm{C}$ improves the bioactivity of the BG-NPs produced, being more effective when the nanoparticles are prepared at $\mathrm{pH} 11.5$.

Nanocomposites resulting from the combination of these materials with chitosan exhibited bioactive character and may be potentially used in a series of orthopedic applications, including in membranes for tissue guided regeneration.

\section{Acknowledgments}

This work was supported by the Portuguese Foundation for Science and Technology (FCT), through project PTDC/QUI/69263/2006 and the PhD grant SFRH/BD/45777/ 2008.

\section{References}

[1] Hench L L 1997 Curr. Opin. Solid State Mater. Sci. 2 604-10

[2] Hench L L 2006 J. Mater. Sci. Mater. Med. 17 967-78

[3] Hench LL A O 1993 An Introduction to Bioceramics vol 1 (River Edge, NJ: World Scientific Publishing Co)

[4] Li R, Clark A E and Hench L L 1991 J. Appl. Biomater. 2 231-9

[5] Gallardo J, Galliano P and Duran A 2001 J. Sol-Gel Sci. Technol. 21 65-74

[6] Sepulveda P, Jones J R and Hench L L 2001 J. Biomed. Mater. Res. 58 734-40

[7] Saravanapavan P, Jones J R, Pryce R S and Hench L L 2003 J. Biomed. Mater. Res. A 66A 110-9

[8] Saravanapavan P and Hench L L 2001 J. Biomed. Mater. Res. 54 608-18

[9] Salinas A J, Martin A I and Vallet-Regi M 2002 J. Biomed. Mater. Res. 61 524-32

[10] Labbaf S, Tsigkou O, Muller K H, Stevens M M, Porter A E and Jones J R 2011 Biomaterials 32 1010-8

[11] Mackay C E, Johns M, Salatas J H, Bessinger B and Perri M 2006 Integr. Environ. Assess Manage. 2 293-8

[12] Hench L L and Thompson I 2010 J. R. Soc. Interface 7 S379-91

[13] Couto D S, Hong Z K and Mano J F 2009 Acta Biomater. 5 115-23

[14] Courtheoux L, Lao J, Nedelec J M and Jallot E 2008 J. Phys. Chem. C 112 13663-7

[15] Bini M, Grandi S, Capsoni D, Mustarelli P, Saino E and Visai L 2009 J. Phys. Chem. C 113 8821-8

[16] Li X, Wang X P, He D N and Shi J L 2008 J. Mater. Chem. 18 4103-9

[17] Perez-Pariente J, Balas F, Roman J, Salinas A J and Vallet-Regi M 1999 J. Biomed. Mater. Res. 47 170-5

[18] Saboori A, Sheikhi M, Moztarzadeh F, Rabiee M, Hesaraki S, Tahriri M and Nezafati N 2009 Adv. Appl. Ceram. $108155-61$

[19] Bordes P, Pollet E and Averous L 2009 Prog. Polym. Sci. 34 125-55

[20] Hu X J, Liu J K, Lu Y and Mu J 2008 Mater. Lett. 62 3824-6 
[21] Yuan J K, Laubernds K, Zhang Q H and Suib S L 2003 J. Am. Chem. Soc. 125 4966-7

[22] Boccaccini A R, Erol M, Stark W J, Mohn D, Hong Z K and Mano J F 2010 Compos. Sci. Technol. 70 1764-76

[23] Hong Z, Liu A, Chen L, Chen X and Jing X 2009 J. Non-Cryst. Solids 355 368-72

[24] Hong Z K, Reis R L and Mano J F 2008 Acta Biomater. 4 1297-306

[25] Hong Z K, Luz G M, Hampel P J, Jin M S, Liu A X, Chen X S and Mano J F 2010 J. Biomed. Mater. Res. A 95A 747-54

[26] Ma J, Chen C Z, Wang D G, Meng X G and Shi J Z 2010 J. Sol-Gel Sci. Technol. 54 69-76

[27] Kokubo T and Takadama H 2006 Biomaterials 27 2907-15

[28] Kim H W, Kim H E and Knowles J C 2005 J. Am. Ceram. Soc. 88 154-9

[29] Brinker C J and Scherer G W 1985 J. Non-Cryst. Solids $70301-22$

[30] Gajovic A, Gracin D, Djerdj I, Tomasic N, Juraic K and Su D S 2008 Appl. Surf. Sci. 254 2748-54
[31] Hong Z, Reis R L and Mano J F 2009 J. Biomed. Mater. Res. A 88A 304-13

[32] Bellantone M and Hench L L 2000 Bioceramics 192-1 617-20

[33] Saravanapavan P, Jones J R, Verrier S, Beilby R, Shirtliff V J, Hench L L and Polak J M 2004 Bio-Med. Mater. Eng. 14 467-86

[34] Hong Z, Merino E G, Reis R L and Mano J F 2009 Adv. Eng. Mater. 11 B25-9

[35] Hench L L 1998 J. Am. Ceram. Soc. 81 1705-28

[36] Lu H H, Pollack S R and Ducheyne P 2000 J. Biomed. Mater. Res. 51 80-7

[37] Benhayoune H, Charlier D, Jallot E, Laquerriere P, Balossier G and Bonhomme P 2001 J. Phys. D: Appl. Phys. 34 141-7

[38] Zhong J P and Greenspan D C 2000 J. Biomed. Mater. Res. 53 694-701

[39] Lin S, Ionescu C, Pike K J, Smith M E and Jones J R 2009 J. Mater. Chem. 19 1276-82

[40] Luz G M and Mano J F 2010 Compos. Sci. Technol. 70 1777-88 